\title{
Strukturiranost odprtega mestnega javnega prostora $v$ uporabnikovi miselni predstavi
}

\begin{abstract}
Javni odprti prostor mesta Doživljanje prostora Miselna predstava o prostoru Mikroambient, Povezovanje Razvrščanje Fizične značilnosti prostora Programske značilnosti prostora.

Classification Experiencing space

Mental perception of space Micro-space

Linkage

Physical properties of space

Članek predstavlja metodo za prepoznavanje kvalitativnih in kvantitativnih razsežnosti odprtega javnega mestnega prostora v uporabnikovi doživljajski sliki. Temelji na domnevi, da odprti prostor mesta $v$ miselni predstavi ni zvezni kontinuum, kar $v$ splošnem velja za njegovo fizično pojavnost. Odkriva, kje in kako doživlja meje konkretnega odprtega javnega prostora, $v$ katerem je, in kaj doživlja kot soseščino takega prostora. Raziskuje torej pravila, po katerih uporabnik fizično kontinuiran odprt javni prostor $v$ mislih strukturira na manjše enote in jih povezujejo med seboj v omrežje. S poznavanjem teh pravil je mogoče odprte javne prostore, ki jih uporabniki doživljajo izrazito pozitivno, na miselni ravni razširiti na širši prostor in tako oživiti tiste sosednje prostore, ki so doživljani $z$ negativno konotacijo ali pa $v$ miselni predstavi sploh niso prisotni in posledično uporabljani. Prav navzočnost ljudi pa je bistvena sestavina kvalitetnega javnega prostora.
\end{abstract} Programmatic properties of space Public open spaces

\section{Opredelitev raziskovalnega problema}

Ena od definicij opredeljuje odprti javni prostor mesta kot prostor med grajenimi strukturami, ki je brez omejitev dostopen vsem, ne glede na njihovo prepričanje, socialni ali ekonomski status. Tako definiran prostor je fizično nepretrgan in se zvezno preliva med grajenimi strukturami. Fizična zveznost se jasno izraža v prikazih morfološke strukture po načelu Gesthalta, v katerih je odprt javni prostor sklenjen lik (pozitiv) in se zvezno razteza med posameznimi objekti (negativi). Spodnja slika prikazuje primer urbanega okolja, zgrajenega na pravokotni ulični mreži z zaprtim karejskim sistemom - v mreži 7 x 7 se teoretično pojavi 16 grajenih objektov, medtem ko je odprt prostor en sam. Podobno velja za
The article presents a method for recognising qualitative and quantitative dimensions of open urban space in the user's perceptual image. It stems from the hypothesis that the open urban space in mental perception isn't a uniform continuum, which in general applies to its physical phenomenon. It discloses where and how users experience the limits of real open public space that they occupy and what they perceive as the neighbourhood of such a place. Therefore it researches rules applied by the user to mentally structure physically continuous space into smaller units and then reassemble these into a network. Knowledge of such rules enables expansion of open urban public spaces, which user's experience as positive, into the wider area, thus revitalising those neighbouring spaces that are perceived as negative or are completely absent in the mental image and consequentially unused. The presence of people is in fact the essential component of quality public spaces.

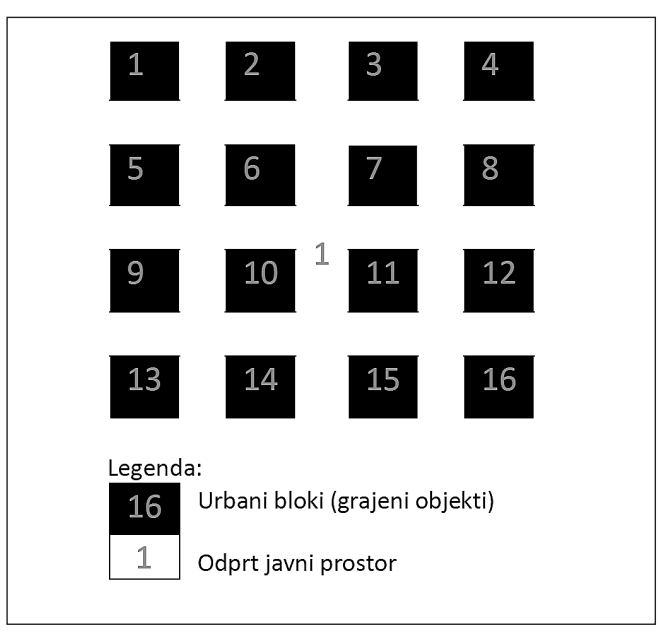

Slika 1: Z vidika fizičnega prostora je razmerje med številom grajenih objektov in številom odprtih javnih prostorov $v$ teoretičnem modelu kompaktnega mesta na mreži $7 \times 7$ 1:16. 
druge morfološke vzorce kompaktno poseljenih urbanih območij.

Iz izkušenj v odprtem javnem prostoru vemo, da kljub njegovi fizični kontinuiranosti v naših miselnih predstavah ni zvezen prostor. Nekateri deli so v teh predstavah bolj, drugi manj prisotni, nekaterih pa sploh ni. Različne so tudi vrednostne sodbe uporabnikov o posameznih delih prostora.

Da bi lahko z urbanističnim oblikovanjem na širši mestni ravni oblikovali pregledno in jasno strukturirano mrežo javnega prostora, je pomembno vedeti, kako in po kakšnih načelih je strukturiran v uporabnikovih miselnih predstavah.

\section{Teoretične osnove}

Osvetlimo najprej razmerje med miselno predstavo, ki je nesnovna kategorija, in prostorom, ki ga tukaj razumemo kot snovno (fizično) kategorijo, na podlagi katere se prva vzpostavi različno.

Po Bellu in sodelavcih (2001) se podoba o prostoru izoblikuje ali neposredno z lastno izkušnjo $\mathrm{v}$ prostoru ali posredno $\mathrm{z}$ informacijami, ki jih dobimo od drugih ljudi, vedno pa $v$ kompleksnem procesu pridobivanja, obdelave in interpretacije informacij, v katerem med posameznimi fazami ni jasnih mej. Pridobivanje informacij najpogosteje poteka $\mathrm{Z}$ neposredno senzorično izkušnjo, v kateri z različnimi čuti (vid, sluh, voh, otip, okus) pridobivamo informacije o okolju, ki nas obdaja. Drugi način pridobivanja informacij poteka prek različnih posrednikov, ki so bolj ali manj objektivni. Med objektivnejše štejemo posnetke prostora (načrti, fotografije, avdio- in videoposnetki ipd.), med manj objektivne pa vire, v katerih se že kaže avtorjeva subjektivna interpretacija, kot so npr. pripovedovanja, slikarije, literarni opisi ipd. (Hudson-Smith, spletni vir).

Zaznava prostora je tudi močno kulturološko povezana. V nekaterih kulturnih sredinah, kjer se še ohranja prvobitni način življenja, je doživljanje prostora še vedno vezano na pomene in simbole. Tako na primer zaznava pri Aboridžinih izhaja iz mitologije oziroma prepričanja, da si ljudje zemlje ne lastimo, ampak smo mi sami njena last oz. del nje (Aboriginal Environments research
Centre, spletni vir). Primerjava z zahodnjaškim odnosom do prostora, $v$ katerem prostor (še vedno) obravnavamo predvsem kot lastnino (Tuan, 2002), s katero lahko prosto razpolagamo, kaže, koliko je dojemanje prostora privzgojeno oziroma temelji na izkušnji v kulturni sredini, v kateri odraščamo oziroma živimo.

\section{Raziskovalne tehnike}

Raziskave zaznavanja urbanega okolja so se razmahnile v drugi polovici prejšnjega stoletja. Mnogo se jih je ukvarjalo z miselno podobo o prostoru kot rezultatom vizualne in kinestetične izkušnje v prostoru. Lynch (1972, 1981) je identificiral načela, po katerih svoje življenjsko okolje strukturiramo v obvladljivo in pregledno celoto s pomočjo petih osnovnih gradnikov: območij, meja, poti, vozlišč in označevalcev prostora. Cullen (1961) je izpostavil pomen, ki ga ima za doživljanje mesta oblikovanje sekvenc vzdolž poti, po kateri se uporabnik giblje. Opozoril je na pomembnost trenutne lokacije uporabnika znotraj kontinuuma odprtega prostora za doživljanje »tukajtam « oziroma orientacijo v mestu in na pomembnost doživljajskih sprememb vzdolž poti, ki jih je možno zagotoviti različno (npr. s spremembami v morfologiji prostora, spremembami v rabi prostora itd.). Eden od uveljavljenih posrednih načinov raziskovanja dojemanja odprtih mestnih prostorov temelji na preučevanju vedenja uporabnikov s t. i. vedenjskimi študijami (ang. behavioural studies). Izhajajo iz domneve, da odločitve o tem, kako bodo uporabniki uporabljali prostor, temeljijo na njihovih miselnih predstavah o teh

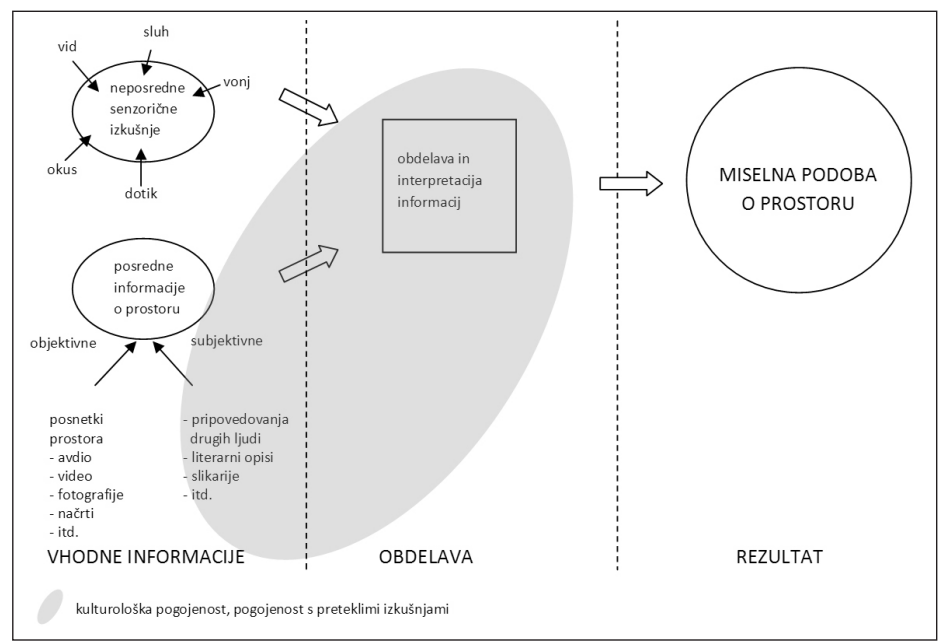

Slika 2: Shema procesa izoblikovanja miselne podobe o prostoru. 
prostorih (Hershenson, 1998). Vedno večja pozornost je namenjena tudi raziskovanju neposrednega vpliva čutov na doživljanje prostora, predvsem vlogi vida, sluha, vonja in dotika (Porteous, 1996). Z razmahom novih oblik komuniciranja pa se vedno več raziskav osredotoča na vpliv mobilnih informacijskih medijev na dojemanje okolja (YouTube, spletni vir).

\section{Raziskovalna vprašanja in zasnova metode}

Da bi razumeli strukturiranje odprtega javnega mestnega prostora $\mathrm{v}$ miselnih slikah uporabnikov, je treba vedeti:

1. kateri oziroma kakšni odprti javni prostori so sploh prisotni v miselnih slikah uporabnikov o določenem urbanem sestavu (četrti, naselju, mestu),

2. kakšne so (v miselnih slikah uporabnikov) kvantitativne in kvalitativne razsežnosti teh prostorov,

3. katere prostore doživljajo uporabniki kot sosednje tem prostorom in kaj jih med seboj povezuje oziroma razmejuje,

4. kaj vpliva na hierarhiziranost teh prostorov $\mathrm{v}$ uporabnikovih predstavah.

Najprej opredelimo osnovne pojme. $M i$ kroambient naj bo tista najmanjša posamezna enota odprtega prostora mesta, ki je skupaj z drugimi v uporabnikovi miselni sliki (torej na miselni ravni) osnovni gradnik mreže odprtega javnega prostora. Izhodiščni mikroambient je tisti mikroambient, v katerem je uporabnik oziroma iz katerega izhaja, ko na miselni ravni strukturira mrežo odprtega javnega prostora. Sosednji mikroambient je vsak mikroambient, ki ga uporabnik dojema kot kakorkoli povezanega z izhodiščnim mikroambientom. Na določen izhodiščni mikroambient se torej lahko navezuje različno število sosednjih mikroambientov. Povezovalni elementi so tiste snovne ali nesnovne značilnosti dveh sosednjih mikroambientov, ki ju v uporabnikovi miselni podobi povezujejo, razmejevalni elementi pa tiste snovne ali nesnovne značilnosti dveh sosednjih mikroambientov, ki ju v uporabnikovi miselni podobi delijo v dva ločena mikroambienta (ki ju uporabnik sicer doživlja medsebojno povezana, a zaradi prepoznanih razločevalnih elementov ne kot ene same enote). Navidezen sosednji mikroambient je vsak odprt prostor mesta, ki fizično meji na izhodiščni mikroambient oziroma je z njim kakorkoli neposredno povezan, vendar ga uporabnik v svoji miselni sliki ne zaznava kot sosednji prostor. Ker ga v uporabnikovi miselni sliki ni, ne more biti predmet tovrstnega preučevanja.

Ker gre za preučevanje nesnovne (miselne) predstave o snovnem (fizičnem) prostoru, je pomembno opredeliti tudi:

1. čigave miselne slike je smiselno proučevati,

2. miselne slike o katerih prostorih proučevati,

3. kateri podatki so pomembni (in jih je treba zbirati),

4. kako podatke zbrati.

Ker je predstava o prostoru izrazito subjektivna in se dokončno oblikuje v glavi vsakega posameznika, so za načrtovanje odprtih mestnih javnih površin pomembne predstave

Preglednica 1: Parametri vzorčenja za preverjanje uporabnikove doživljajske slike o odprtem javnem prostoru mesta, z utemeljitvami.

\begin{tabular}{|l|l|l|l|}
\hline \multicolumn{1}{|c|}{ Vidik } & \multicolumn{2}{|c|}{ Vhodni podatek (bolj/manj objektiven) } & \multicolumn{1}{c|}{ Utemeljitev } \\
\hline $\begin{array}{l}\text { pogostost interakcije } \\
\text { s prostorom }\end{array}$ & naslov bivanja/zaposlitve & $\begin{array}{l}\text { uporabnikova ocena po- } \\
\text { gostosti zadrževanja ozi- } \\
\text { roma uporabe obravnava- } \\
\text { nega prostora }\end{array}$ & $\begin{array}{l}\text { ljudje s stalnim bivališčem in/ali delovnim mestom } \\
\text { v obravnavanem prostoru so zelo verjetno v pogosti } \\
\text { interakciji s preučevanim prostorom }\end{array}$ \\
\hline življenjski stil & $\begin{array}{l}\text { najpogostejše destinacije } \\
\text { preživljanja prostega } \\
\text { časa }\end{array}$ & $\begin{array}{l}\text { prijubljene prostočasne } \\
\text { aktivnosti }\end{array}$ & $\begin{array}{l}\text { kraj/način preživljanja prostega časa zelo verjetno } \\
\text { nakazujeta, v kakšnem prostoru se uporabnik rad } \\
\text { zadržuje }\end{array}$ \\
\hline izvor (kulturna sredina) & materni jezik & $\begin{array}{l}\text { uporabnikova ocena } \\
\text { pripadnosti kulturni } \\
\text { sredini }\end{array}$ & $\begin{array}{l}\text { materni jezik zelo verjetno opredeljuje osnovne } \\
\text { kulturološke vzorce, pridobljene v času osebnostnega } \\
\text { formiranja }\end{array}$ \\
\hline $\begin{array}{l}\text { osnovne statistične } \\
\text { kategorije }\end{array}$ & spol, starost, izobrazba & & \\
\hline
\end{tabular}


vseh tistih, ki prostor uporabljajo oziroma ga poznajo. Vzorčenje je smiselno izvajati glede na naslednje vidike oziroma skupine uporabnikov:

- pogostostost zadrževanja v prostoru (domnevamo lahko, da so predstave uporabnikov, ki so s preučevanimi prostori $\mathrm{v}$ vsakdanji interakciji, drugačne od predstav tistih, ki jih uporabljajo manj pogosto),

- priljubljene oblike preživljanja prostega časa (domnevamo lahko, da so predstave ljudi, ki jim je urbani način življenja blizu, drugačne od predstav ljudi, ki svoj prosti čas raje preživljajo v naravnem okolju),

- kulturno sredino, iz katere uporabnik izhaja (ker je zaznava kulturološko pogojena, lahko domnevamo, da so predstave uporabnikov, ki izhajajo iz avtohtone kulturne sredine, različne od predstav uporabnikov, ki izhajajo iz drugih kulturnih sredin),

- pa tudi predstave uporabnikov glede na osnovne statistične kategorije: spol, starost in izobrazbo.

Izbira konkretnega prostora raziskovanja izhaja neposredno iz vprašanja, katere so glavne značilnosti tistih odprtih javnih prostorov mesta, ki so prisotni v uporabnikovi miselni predstavi o njem. Čeprav nas preučevani fenomen zanima na mikroravni konkretnih prostorov, je treba izhajati iz širšega prostorskega konteksta - ravni četrti, soseske ali celo mesta. Po Lynchu (1972) si ljudje izoblikujemo o mestih miselno predstavo oz. podobo (ang. mental image), ki izraža vsebino in načrt mesta glede na naše osebno doživljanje, njen grafični izraz pa so miselni zemljevidi. Posamezni odprti javni prostori mesta, ki se na teh zemljevidih pojavijo, so torej primerni študijski primeri. Za dokončno izbiro sta pri teoretičnih raziskavah pomembni pogostost priklica (kako pogosto so se pojavili) in raznolikost $\mathrm{v}$ morfološki tipologiji prostorov (linijski $<>$ ploskovni, tlakovani $<>$ ozelenjeni itd.). Po nekaterih raziskavah (Hershenson, 1998) je zaradi omejitev človeškega spomina sedem tisto število, ki ga v delovnem spominu še lahko obvladamo, zato je smiselno preučevati največ sedem enot naenkrat.

Izrazita subjektivna pogojenost raziskovalnega fenomena in kvalitativna naravnanost raziskave narekujeta izbor raziskovalne tehnike, ki lahko da poglobljen vpogled v posameznikovo doživljanje prostora in hkrati omogoča splošne ugotovitve. Po Kvaleju
(1996) je intervju najprimernejše orodje na poti k razumevanju posameznikovega doživljanja življenja in sveta. Raziskovalec lahko z intervjujem posluša, kaj ljudje sami povedo o svetu, ki ga živijo, sliši njihove poglede in mnenja, izražena $z$ njihovimi lastnimi besedami, se pouči o njihovih delovnih in življenjskih situacijah, načrtih in upih. Kvalitativni intervju je po Kvaleju »notranji pogled oziroma pogled $v$ notranjost « (ang. inter view, str. 296). Namen intervjuja je "pridobiti opise żivega sveta intervjuvanca $s$ pozornostjo interpretaciji pomena opisanega fenomena « (str. 5). Tudi zato je intervju še posebno primerna tehnika za preučevanje miselne podobe (Yin, 2003).

Ko so študijski primeri izbrani, je intervjuvance treba miselno umestiti v preučevane prostore oziroma jih seznaniti, kam natančno naj se med intervjujem miselno locirajo. Domnevamo lahko, da poseben položaj v prostoru (v središču/na robu trga, parka, ulice itd.) zaradi mikromerila preučevanega fenomena pomembno vpliva na zaznavo, zato ga je treba jasno definirati (npr. $\mathrm{Z}$ znakom $\mathrm{X}$ na zemljevidu). Miselno uvajanje v preučevani prostor lahko poteka različno, npr. Z načrti mesta, panoramskimi ali letalskimi posnetki, fotografijami ipd., ki pa morajo biti dovolj splošni, da na intervjuvanca kakorkoli vrednostno ne vplivajo.

Da bi bili odgovori intervjuvancev v končni fazi primerljivi, je treba intervju strukturirati. Vprašanja glede na njihovo vlogo v procesu raziskovanja lahko razdelimo v pet skupin:

- uvajalna vprašanja - namenjena temu, da se intervjuvanec miselno umesti v preučevani prostor;

- kvantitativna vprašanja - preučujejo (merljive) fizične razsežnosti preučevanega prostora;

- kvalitativna vprašanja - preučujejo (nemerljive) vrednostne sodbe o preučevanem prostoru;

- vprašanja za prepoznavanje medsebojnih povezav - ugotavljajo, kateri vidiki igrajo ključno vlogo pri miselnem strukturiranju odprtega mestnega prostora na posamezne enote;

- vprašanja za preverjanje - preverjajo, ali gre za trenutno ali ustaljeno predstavo o prostoru.

V nadaljevanju je podanih nekaj primerov takih vprašanj. 
Primeri vprašanj za preverjanje razsežnosti posameznih odprtih javnih prostorov v miselni sliki uporabnika ter njihove medsebojne hierarhizacije:

- Predstavljajte si, da stojite na kraju, ki je na zemljevidu zaznamovan $\mathrm{z}$ X. Označite, kje po vašem mnenju potekajo meje prostora, v katerem ste.

- Katere so po vašem mnenju glavne značilnosti tega prostora? Naštejte poljubno število značilnosti.

- Med navedenimi značilnostmi imenujte tiste, ki so po vašem mnenju pozitivne, in tiste, ki so po vašem mnenju negativne. Če se ob tem spomnite še novih značilnosti, jih izrazite in se do njih opredelite enako.

- Na zemljevidu označite meje vseh sosednjih prostorov, ki se po vašem mnenju navezujejo na prostor, ki ste ga že označili. Oštevilčite te prostore $\mathrm{z}$ zaporednimi številkami tako, da s št. 1 označite tistega, ki je po vašem mnenju najbolj povezan s prostorom X, s št. 2 tistega, ki je naslednji najbolj povezan, itd.

- Za vsakega od oštevilčenih prostorov navedite njegove glavne značilnosti. Za vsak prostor naštejte poljubno število značilnosti.

- Med navedenimi značilnostmi imenujte tiste, ki so po vašem mnenju pozitivne, in tiste, ki so po vašem mnenju negativne. Če se ob tem spomnite še novih značilnosti, jih izrazite in se do njih opredelite enako.

- Utemeljite, zakaj je prav prostor, označen s št. 1, od vseh označenih prostorov najbolj povezan s prostorom $\mathrm{X}$.

- Utemeljite, zakaj je prav prostor, označen z najvišjo številko, najmanj povezan s prostorom X.

Primeri vprašanj za preverjanje vpliva načina uporabe in neposrednih okoljskih dražljajev na doživljanje medsebojne hierarhizacije posameznih odprtih javnih prostorov v miselni sliki uporabnika:

- Na zemljevidu vrišite pot, po kateri se najpogosteje gibljete skozi prostore, ki ste jih označili na zemljevidu.

- S kakšnim razlogom in kako (peš, s kolesom, avtom itd.) najpogosteje uporabljate to pot? Ali je to najkrajša pot (če ne, zakaj greste ravno po tej)?

- Na zemljevidu vrišite pot, po kateri bi skozi označene prostore peljali turista, ki prostora še ne pozna. Komentirajte, zakaj bi ga peljali ravno tam.

- Če bi stali na kraju, označenem z X, in bi imeli možnost posneti eno samo fotografijo, v katero smer bi slikali?
- Narišite ta pogled. Imenujte vse tisto, kar se vam zdi za ta pogled bistveno.

- Predstavljajte si, da stojite na kraju X in zaprete oči. Katere zvoke slišite? Če ste našteli več zvokov, imenujte tistega, ki je po vašem mnenju prevladujoč oz. najbolj značilen za ta prostor.

- Ali se ta zvok (prevladujoč oz. najbolj značilen) pojavlja tudi v katerem od sosednjih prostorov, ki ste jih na zemljevidu oštevilčili (če da, v katerih)?

- Predstavljajte si, da stojite na kraju X in zaprete oči. Katere vonjave zaznavate? Če ste našteli več vonjav, imenujte tisto, ki je po vašem mnenju prevladujoča oz. najbolj značilna za ta prostor.

- Ali se te vonjave pojavljajo tudi v katerih od sosednjih prostorov, ki ste jih oštevilčili na zemljevidu (če da, v katerih)?

- Predstavljajte si, da se morate s prsti dotakniti poljubne stvari v prostorih, ki ste jih označili na zemljevidu - česa bi se najraje dotaknili? Zakaj bi se najraje dotaknili prav tega?

- Predstavljajte si, da se morate bosi sprehoditi po poljubni površini v prostorih, ki ste jih označili na zemljevidu. Kje bi se najraje sprehodili? Zakaj bi se najraje sprehodili ravno po tej površini?

\section{Obdelava in prikaz podatkov}

Podatke, pridobljene z intervjujem, je treba spremeniti v pregledno obliko, ki je načrtovalcu v pomoč pri odločanju o konkretnih posegih v prostor. Z intervjuji zbrane podatke je zaradi preglednosti in križanja podatkov smiselno prikazovati v okolju GIS, saj omogoča enostavno analiziranje ter primerjanje z drugimi prostorskimi bazami.

V nadaljevanju so predstavljeni nekateri prikazi, ki združujejo kvalitativne in kvantitativne podatke, kot so:

1. fizične dimenzije izhodiščnega mikroambienta samega (do kod $\mathrm{v}$ uporabnikovi miselni predstavi sega),

2. fizične dimenzije izhodiščnega mikroambienta skupaj s sosednjimi mikroambienti (na kaj se v uporabnikovi miselni predstavi prostor povezuje),

3. značilnosti posameznih mikroambientov (izhodiščnega in sosednjih) ter vrednostne sodbe o teh značilnostih,

4. vrednostne sodbe o teh značilnostih,

5. povezovalni in razmejevalni elementi med mikroambienti. 
Karta doživljane meje mikroambienta (ali kratko karta meje) je karta, na kateri je linijsko označena meja prostora, kot jo doživlja uporabnik s stojišča X (na spodnji sliki npr. 1). Iz načrtovalskega vidika je najbolj merodajna skupna karta doživljanih meja mikroambienta (na spodnji sliki 123...n), ki je seštevek posameznih. Na njej so skupaj prikazane meje prostora, kot jih doživlja več uporabnikov. Kjer se linije zgoščajo ali celo prekrivajo, govorimo o t. i. splošno doživljani meji mikroambienta. Zunanji obod celotne karte (ki je na spodnji sliki označen $\mathrm{z}$ debelo črto) pa je t. i. maksimalna doživljana meja mikroambienta.

Karta intenziunosti pripadnosti mikroambientu (ali kratko karta intenzionosti) je karta, ki prikazuje, kako močno so posamezni deli znotraj maksimalne meje mikroambienta doživljani kot njegovi sestavni deli. V primeru posameznikovega doživljanja (v spodnji sliki npr. 1) je ta intenzivnost enaka za celoten mikroambient. Pomembna je skupna karta intenzivnosti pripadnosti mikroambientu, ki prikazuje doživljanje več uporabnikov hkrati. Grafični prikaz se generira $z$ enostavnim seštevanjem sivin posameznih kart - temnejše je območje v skupni karti, več uporabnikov ga doživlja kot del obravnavanega mikroambienta.

Karta povezovanja mikroambienta z okolico (ali kratko karta povezovanja) prikazuje, kako uporabnik doživlja povezanost izhodiščnega mikroambienta s sosednjimi mikroambienti. Je najkompleksnejša, saj poleg vsebin dveh prej opisanih kart enake vsebine prikazuje tudi za vse sosednje mikroambiente. Ker posamezniki kot sosednje doživljajo različno število mikroambientov, je pri obdelavi podatkov potrebno poenotenje $\mathrm{v}$ kategorije, kot prikazuje spodnja tabela. Prikazovanje v okolju GIS omogoča, da lahko s klikom na posamezno mejo neposredno preverjamo npr. povezovalne in razmejevalne elemente ipd. V kombinaciji z morfološko karto prostora je možno identificirati tudi navidezne sosednje prostore (ti na karti ostanejo brez sivin)

Razpredelnica 2 z legendo: Posamezniki glede na izhodiščni mikroambient doživljajo različno število sosednjih mikroambientov. Tabela prikazuje primere, ko uporabnik zazna $3,4,5 \ldots$ ali 10 sosednjih prostorov (latinske številke). Da so medsebojne primerja- ve možne, je potrebno pretvarjanje v primerljive kategorije (rimske številke I-VII) glede na to, kako močno povezanost z izhodiščnim mikroambientom uporabnik doživlja (med intervjujem to izrazi s številčenjem sosednjih mikroambientov od 1 dalje - glej tudi razpredelnico 2). Sosednji mikroambienti, ki so doživljani kot najbolj (statistično 100 \%) povezani $z$ izhodiščnim mikroambientom, spadajo v kategorijo I, tisti, ki so doživljani kot najmanj (statistično $0 \%$ ) povezani z izhodiščnim mikroambientom, v kategorijo VII. V grafičnih prikazih vsaki od kategorij pripada določen odtenek sive barve po načelu, da imajo mikroambienti, ki jih uporabniki doživljajo kot bolj povezane z izhodiščnim mikroambientom, temnejši odtenek.

Intervjuji dajejo tudi podatke o kvalitativnih značilnostih mikroambientov. Smiselno jih je združevati glede na tri osnovne kategorije, ki so jih pretekle raziskave že opredelile kot bistvene za vzpostavljanje identitete prostora (Punter, 1991, Montgomery, 1998):

- fizične značilnosti (npr. ulično pohištvo, grajena struktura, ritem, razmerja, materiali itd.),

- programske značilnosti (npr. ulično življenje, dogodki, dejavnosti, ponudba v odprtem prostoru in $\mathrm{v}$ robnih objektih itd.),

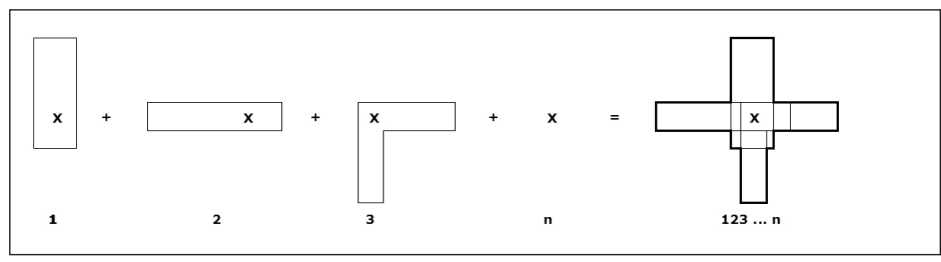

Slika 3: Skupna karta meje je seštevek posameznih.

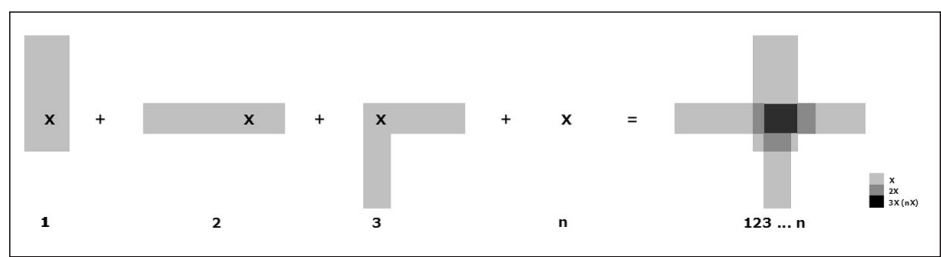

Slika 4: Karta intenzivnosti je seštevek posameznih.

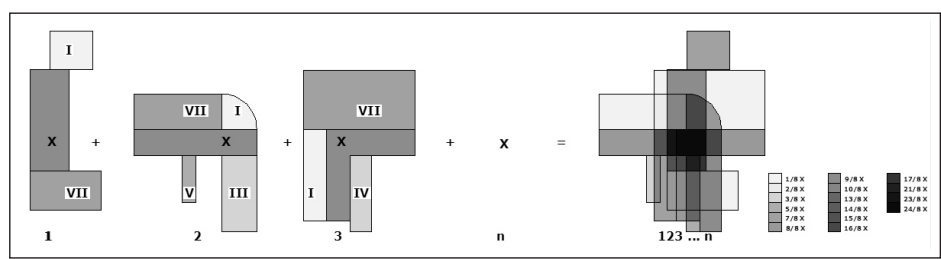

Slika 5: Končna karta povezljivosti mikroambienta je seštevek posameznih. Temnejši odtenek pomeni večjo povezanost z izhodiščnim mikroambientom. 
- simbolno-pomenske značilnosti (simbolika, spomini, asociacije, čitljivost itd.)

V okolju GIS se ti podatki lahko prikazujejo na dva načina:

- V obliki tabel se pripenjajo posameznim poligonom, ki označujejo doživljane meje mikroambientov. Do njih je torej možno dostopati enostavno s klikom.

- Grafično z upoštevanjem načel mešanja treh osnovnih barv oziroma barvnega kroga. Za vsak mikroambient se izračuna število fizičnih, programskih in simbolnopomenskih značilnosti in se glede na njihovo medsebojno razmerje generira barva, kot prikazuje spodnja slika - število fizičnih značilnosti pomeni število enot modre barve, število funkcijskih značilnosti število enot rdeče barve in število simbolnih značilnosti število enot rumene barve. Tako nastane karta doživljane identitete mikroambienta (ali kratko karta identitete).

\section{Pričakovani rezultati in uporabnost} za potrebe urbanističnega načrtovanja

Pričakovani prispevek predstavljene metode $\mathrm{k}$ urbanističnemu načrtovanju je dvojen:

- Na teoretični ravni dopolnjuje vedenje o tem, kaj vpliva na strukturiranje odprtega mestnega javnega prostora $\mathrm{v}$ miselnih podobah uporabnikov, in dokazuje, da je odprt prostor mesta $\mathrm{v}$ nasprotju $\mathrm{z}$ njegovo fizično pojavnostjo $v$ miselni podobi uporabnikov strukturiran v posamezne, razmeroma majhne in bolj ali manj jasno zamejene enote, t. i. mikroambiente.

- Za praktično rabo je orodje za vpogled v konkretno doživljanje prostora uporabnika ali skupine uporabnikov. $Z$ njo je mogoče prepoznati potrebne fizične in programske posege $\mathrm{v}$ prostor, da bi ta postal všečen. Ponuja tudi konkretne odgovore na vprašanje, kako fizično in programsko oblikovati in urejati odprt prostor mesta, da bo integriran z drugimi prostori in $\mathrm{v}$ miselni sliki sestavni del mreže odprtega javnega prostora na ravni mesta. Javni prostori, ki so jasno prepoznani kot integralni del širšega sistema, bodo bolj verjetno uporabljani zadrževanje ljudi $\mathrm{v}$ javnih prostorih mesta pa je eden od osnovnih kazalcev kakovosti urbanega okolja.
$\mathrm{V}$ prihodnje je treba preveriti dodatne možnosti za (hitrejše) zbiranje in obdelavo podatkov, ki bodo omogočali oblikovanje baze podatkov na podlagi doživljanja čim širšega kroga uporabnikov.

Matej Nikšič, univ. dipl. inž. arh., Urbanistični inštitut Republike Slovenije, Ljubljana

e-pošta: matej.niksic@uirs.si

\section{Viri in literatura}

Aboriginal Environments research Centre. The University of Queensland, Brisbane, Australia. Spletni dostop: http://www. aboriginalenvironments.com/index.html.

Bell, P. A. et al. (2001). Environmental psychology. Fifth edition. Belmont: Thomson Wadsworth.

Cullen, G. (1961). Townscape. London: Architectural press.

Hershenson,M. E. (1998). Visual Space Perception. A Primer. Cambridge: MIT Press.

Hudson-Smith, A. Digital Urban. Spletni dostop: http://digitalurban.blogspot.com/2005/10/about-digitalurban.html.

Kvale, S. (1996). Interviews. An Introduction to Qualitative Research Interviewing. Thousand Oaks: Sage Publications, Inc.

Lynch, K. (1972). The Image of the City. Cambridge, London: The MIT Press.

Lynch, K. (1981). Site Planning. Massachusetts: Massachusetts Institute of Technology.

Porteous, J. D. (1996). Environmental Aesthetics. Ideas, politics and planning. London: Routledge.

Tuan, Y. (2002). Space and Place. The Perspective of Experience. Minneapolis, London: University of Minnesota Press.

Yin, R. K. (2003). Case study research. Design and methods. Third edition. Thousand Oaks, London, New Delhi: SAGE Publications.

YouTube. Ipod Culture - Perception of Urban Space Now with YouTube Movies. Spletni dostop: http://digitalurban.blogspot.com/2006/04/ipod-culture-perception-of-urban-space.html. 